\title{
A Penny for Your Thoughts: Exploring Experiences of Engagement, Voice, and Silence
}

\author{
Russell Robinson \\ University of Louisville \\ Brad Shuck \\ University of Louisville
}

This qualitative content analysis study explores the experiences of public sector employees' decisions to share and not share their ideas with leadership, and how those decisions relate to their engagement states. We found that the relationship with supervisors can impact both employee voice and silence. Further, employee voice is impacted by the power of ideas and how the idea is crafter. And, employee silence was impacted by previous voice experiences and job insecurity. Last, we position that the employee voice/silence decisions are outcomes of the employee engagement state, compared to being a driver.

Keywords: Employee Engagement, Employee Voice, Employee Silence, Public Sector

\section{INTRODUCTION}

Public sector employees are the front lines of the work for their respective agencies. They have ideas, thoughts, and concerns that could benefit their agencies in meeting common good missions. Daily, these employees choose to either share or not share their ideas, which can have both positive and negative impacts to their agencies and the American citizens. The purpose of this qualitative content analysis was to explore experiences of exercising voice and silence and understand their relationship of the engagement state of public sector employees. Findings indicated that, in addition to supervisor relationship, factors such as confidence, insecurity, message impact, strategic planning, and previous experiences impacted voice and silence decisions. Additionally, there are inconsistencies regarding the positioning of employee voice and silence with employee engagement. Being able to understand these experiences are beneficial to develop communication structures to foster employee voice. The implications for leadership development practices and employee engagement research are discussed.

\section{LITERATURE REVIEW}

\section{Employee Engagement}

Within the public-sector there is an evolving discussion regarding the importance of employee engagement as a medium for driving the various outcomes, such as performance and well-being (Macleod 
\& Clarke, 2009). The purpose of most public-sector organizations is not to generate revenue, but to achieve goals that collectively provide for the common good. This can mean defending the nation, enforcing laws, educating our children, putting people back to work, caring for an aging population, providing service to veterans, or solving problems like poverty and homelessness (Lavigna, 2013). Additionally, Robinson (2017) suggested public sector leaders face the challenge of identifying practices to ensure that employees sustain their engagement through the changes and challenges of working in federal service. Further, Macleod and Clarke (2009) suggested that employee engagement strategies enable people to be the best they can be at work, recognizing that this can only happen if they feel respected, involved, heard, well-led, and valued by those they work for and with. Therefore, understanding employee engagement helps to understand and improve public servants' work experience, ensuring that they have access to the opportunities needed to achieve success in their roles, which, in turn, supports agencies' drive to deliver improved public services and better outcomes for citizens (Alfes \& Leloglu, 2013).

In his seminal work on personal engagement and disengagement, Kahn (1990) conceptualized three antecedent drivers of employee engagement—psychological safety, psychological meaningfulness, and psychological availability. People have dimensions of themselves that, given appropriate conditions, they prefer to employ and express during the roles they perform, even as they maintain boundaries between whom they are and the roles they occupy (Kahn, 1990). Wollard and Shuck (2011) suggested that focusing on antecedents to engagement could have positive impact on developing a plan to engage the workforce. Further, Wollard and Shuck stated that practitioners who can identify potential antecedents within their organization may be better equipped to present viable strategies to stakeholders, identify potential challenges, and communicate with clearer vision and direction. In the work environment, individuals vary their willingness to invest themselves according to the benefits, or the meaningfulness, and the guarantees, or the safety, they perceive in situations, as well as according to the resources they perceive themselves to have, or their own availability (Crawford, Rich, Buckman, \& Bergeron, 2013). Research by May, Gilson, and Harter (2004) found that psychological meaningfulness, psychological safety, and psychological availability were significantly related to engagement. Connected, these three drivers are used by an employee, consciously and subconsciously, when determining their level of engagement (Kahn, 1990).

There are several potential outcomes of employee engagement. For example, Lavigna (2013) suggested that higher levels of employee engagement correlated with higher rates of success achieving strategic goals, higher employee retention, fewer days of sick leave and less lost time due to work-related injury or illness, and fewer equal employment opportunity complaints. And, Shuck and Rose (2013) theorized that leaders who develop high levels of employee engagement within their organizations enjoy increased levels of competitive advantage. Further, Albrecht and his colleagues (2015) suggested that employee engagement has an impact on a myriad of individual outcomes, such as job satisfaction, commitment, and retention, as well as organizational outcomes, such as innovation and financial returns. Additionally, the CIPD (2010) suggested that employee engagement has direct impacts on job performance and behavior, and an inverse impact on intent-to-turnover.

Research by Shuck and his colleagues (2011) found that employee engagement impacts various individual and organizational outcomes, which encompass discretionary efforts and intent-to-turnover. Discretionary effort is defined as the voluntary effort employees exert that lies above the minimum level of effort required to keep the job and is directed toward organizational goals (Lloyd, 2008). The goal of discretionary effort is getting people to contribute more than their job strictly requires (Lloyd, 2008). Macleod and Clarke (2009) stated that "employee engagement is two-way: organizations must work to engage the employee, who in turn has a choice about the level of engagement to offer the employer" (p. 19). Shuck and his colleagues (2012) identified discretionary effort as being fragile aspect of employee engagement because the employee is making a conscious choice to invest personal resources in his/her work. 


\section{Employee Voice}

Employees feel that being listened to is the most important factor in determining how much they valued their organization (Macleod \& Clarke, 2009). Morrison (2011) suggested that employees expressing their voice can have positive organizational impacts. However, Milliken and her colleagues (2003) theorized that employees often do not feel comfortable speaking to their bosses about organizational problems or issues that concern them. Sometimes the results can be employees withholding such input, choosing to exhibit their silence, and depriving their organization of potentially useful information, which can have negative organizational impacts (Morrison, 2014).

Employee voice was originally defined as an economic complaint mechanism for customers (or employees) to express their concerns to the organization (or management) (Hirschman, 1970). This early work on voice focused unions as the main instrument of employee thoughts and concerns (Barry \& Wilkinson, 2015). Hirschman's theory was that when employees or customers were confronted with negative or unsatisfactory conditions in the work environment, they would either exit or express their voice, which aligned to the outcomes of intent-to-turnover and discretionary effort, respectively (Kassing, 2002). In this construct, loyalty was a moderating variable that would influence employee responses to the negative or unsatisfactory conditions; loyalty has a direct relationship with voice and an inverse relationship with exit (Kassing, 2002).

From the organizational behavior (OB) field, the perspective of voice is an extra-role behavior used to challenge the status quo (Mowbray, Wilkinson, \& Tse, 2014). Yet, voice is more in line with a focus on mechanisms that allow for individual employee involvement, such as task-based participation, upward communication, and problem-solving (Mowbray et al., 2014). In this construct, the driving force behind voice is presumed to be the desire to bring about constructive change for the organization as a collective (Morrison, 2011). In this vein, Van Dyne, Kamdar, and Joireman (2008) found employees that have high duty-orientation and strong relationships with their supervisor are more likely to engage in voice. For example, Gruman and Saks (2014) argued that an employee who has learned from experience that her supervisor is uninterested in hearing anyone else's ideas is likely to acquiesce to the supervisor's suggestions, reluctantly express agreement with his ideas, and only offer new suggestions that are in line with the supervisor's existing agenda.

\section{Employee Silence}

Different from employee voice, Tangirala and Ramanujan (2008) posited employees frequently choose to remain silent about important issues at work. Milliken and her colleagues (2003) suggested that there is evidence that employees choose to remain silent because of not feeling comfortable speaking up to their bosses about organizational problems or issues that concern them. Morrison (2014) expanded this assertion by suggesting that when employees withhold such input, they are choosing to exhibit their silence and depriving their organization of potentially useful information. Therefore, employee failure to speak up with concerns or ideas can have small to dire consequences for an organization (Detert \& Trevino, 2010).

This alternative to employee voice is employee silence. Withholding information and ideas can undermine organizational decision-making, error correction, and the innovation process (Vakola \& Bouradas, 2005). Morrison and Milliken (2000) stated that within organizations there is a paradox where employees know the truth about certain issues and problems within the organization but choose to not exercise their voice to supervisors and, consequently, their leaders. Milliken et al. (2003) suggested employees are especially uncomfortable conveying information about potential problems or issues to those above them. And this reluctance to share information, speak up, or provide feedback has the potential to negatively affect employee trust, morale, and motivation, which are antecedents to employee engagement (Vakola \& Bouradas, 2005). 


\section{RESEARCH AND COLLECTION METHODS}

This study utilized qualitative content analysis as its form of research. Forman and Damschroder (2008) suggested that qualitative content analysis examines data in the product of open-ended data collection techniques aimed at detail and depth, instead of measurement. Additionally, qualitative content analysis delves deeper than simply counting certain words or counting certain types of content, especially for the case of emergent studies; and, allows for a deeper understanding by extracting overall themes and patterns (Zhang \& Wlidemuth, 2009). Last, qualitative content analysis gives attention to unique themes that illustrate the range of the meanings of the phenomenon rather than the statistical significance of the occurrence of texts or concepts (Zhang \& Wlidemuth, 2009).

Creswell's (2013) general concept and process guided the data collection protocol for this study. Creswell suggested data collection also involved gaining permissions, conducting a good qualitative sampling strategy, developing means for recording information both digitally and on paper, storing the data, and anticipating ethical issues that may arise. In addition, Creswell conceptualized data collection as a series of interrelated activities aimed at gathering good information to answer emerging research questions. As stated, the data collected consisted of an initial questionnaire and semi-structured interview sessions.

For this study, 14 full-time employees were interviewed. These employees consisted of males and females that were currently working full-time for the U.S. federal government. To maximize the possibility that the participants would have experienced engaging in employee voice, silence, and engagement while employed in the federal government, a length of employment criterion was implemented during participant recruitment. The length of employment required for participating in this study was five years and participants had to be currently employed at a U.S. federal agency.

There were no predetermined demographics, such as name of agency, age, gender, or race; however, the sample contained participants from eight large-level agencies and two independent federal agencies. The years of federal service ranged from the research minimum of five years to 28 years, with the average tenure being 15 years. Of the sample, $64 \%$ were female. Based on how the participants self-identified, the racial make-up of the participant sample was as follows: African-American $50 \%$, Caucasian $32 \%$, Hispanic 11\%, and Asian-American 7\%. Pertaining to salary, the sample contained employees from General Schedule (GS)-11 to the Senior Executive Services (SES) with the following breakdown: GS-11, 14\%; GS-12, 7\%; GS-13, 7\%, GS-14, 14\%, GS-15, 50\%, and SES, 7\%. Regarding the age range of the participant sample, the following breakdown was formulated: $26-35$ years, $23 \%$; 36-45 years, 21\%; 46-55 years, 28\%; and over 56 years, $28 \%$. All but one interview was conducted face-to-face. The interview for that one person was conducted via Skype. The duration of the interviews lasted from slightly under 29 minutes to slightly over 63 minutes, with an average interview length of 50 minutes. Digital recordings of interviews were transcribed in their entirety. To ensure accuracy, each transcription was read against its source digital recording.

There were several steps to conducting interviews. Each interview began with explanations of both the purpose of the study and the process to ensure the participant's confidentiality and anonymity. Next, participants were asked to reflect and then describe instances where they had ideas, thoughts, and concerns (ideas) that could improve their workplace and/or agency. Then, participants were asked to reflect and describe instances when they chose to share, and not share, those ideas with supervisors and leaders. To capture the richness of their experiences, participants were asked to describe reasons and impacts of sharing and not sharing their ideas with supervisors and leaders. Last, participants were asked whether their decisions to share and not share ideas where drivers or outcomes of their feelings of being engaged. 


\section{DATA ANALYSIS}

This study asked participants three primary questions: (a) why they choose to share their ideas with supervisors and leaders, (b) why they choose to not share their ideas with supervisors, and (c) how those decisions relate to their feelings of being engaged.

Two basic coding processes were used throughout interview transcripts. First, a-priori codes based on the literature review were developed. Next, emergent codes were identified during the analysis process. These codes captured themes, ideas and patterns that were not captured in the literature review. The combination of both sets of codes offered the most robust analysis of the data because it combined both apriori and open coding findings to emerge.

Using Saldana (2016) as a guide, two cycles of coding were performed which resulted in these nine group codes contained 47 codes. The breakdown for the 47 codes was as follows: (a) 34 codes for the a priori code list; (b) 10 codes in the emergent codes list; (c) two codes from the Voice/Silence Relates to Engagement code group; and (d) one code from the Leading Engagement code group. See Table 1.

\section{TABLE 1}

\section{CODE BREAKDOWN}

\begin{tabular}{llc}
\hline Group Code & Code & Frequency \\
\hline Emergent Code & Complacency & 28 \\
& Frustration & 33 \\
& Impact on Others & 9 \\
& Intent-to-Retire & 7 \\
& Leadership Tenure & 16 \\
& Learning & 11 \\
& Morale & 11 \\
& Previous Experience of Self & 7 \\
& Strategic Planning & 63 \\
& Well-Being & 5 \\
\hline Employee Silence & Communication Structure & 38 \\
& Futility & 81 \\
& Retribution & 18 \\
\hline Employee Voice & Address Problem & 41 \\
& Previous Experience of Others & 13 \\
& Provide Ideas & 103 \\
& Supervisor Relationship & 58 \\
\hline Engagement Outcomes & Discretionary Effort & 50 \\
& Intent-to-Turnover & 36 \\
& Retention & 18 \\
\hline Leading Engagement & Training & 10 \\
\hline Psychological Availability & Burnout & 8 \\
& Confidence & 21 \\
& Emotional Energy & 8 \\
& Exhaustion & 6 \\
& Insecurity & 14 \\
& Outside Life & 41 \\
& Physical Resources & 21 \\
\hline
\end{tabular}




\begin{tabular}{llc}
\hline Group Code & Code & Frequency \\
\hline Psychological Meaningfulness & Autonomy & 15 \\
& Empowerment & 13 \\
& Feeling Valued & 57 \\
& Flow & 3 \\
& Impact on Mission & 60 \\
& Job Challenge & 26 \\
& Job Fit & 6 \\
& Recognition & 7 \\
\hline Psychological Safety & Communication & 60 \\
& Culture & 146 \\
& Impact of Supervisor & 140 \\
& Interpersonal Relationships & 43 \\
& Leadership Style and Process & 244 \\
& Openness & 43 \\
& Seeking Feedback & 29 \\
& Sharing Information & 26 \\
& Trust & 68 \\
\hline Voice/Silence Relates to Engagement & Engagement Precedes Voice & 27 \\
& Voice Precedes Engagement & 3 \\
\hline
\end{tabular}

As the last step in the compilation process, "post-coding" and "pre-writing" were performed to further the migration from codes to the emergence of themes. Saldana (2016) described the "post-coding" and "pre-writing" process as a transitional analytic process between coding cycles and the final write-up of the research study. To matriculate from codes to the emergence of themes, the researcher developed first developed a code book for the emergent codes established during the first and second coding cycles.

\section{FINDINGS}

\section{How Do Public Sector Employees Experience Engaging in Voice?}

Public sector employees experience sharing ideas in a myriad of different ways and from different vantage points. However, these articulations have commonality based on three stages: (a) the worker articulating an idea, thought or concern to his/her supervisor or leadership; (b) the worker's belief that his/her supervisor or leadership will listen to the worker's articulation; and (c) the worker's belief that his/her articulation can have impact on the workgroup or the organization. One of the study participants, Chantal, captured these voice stages, "Having a voice is when staff feel that they can raise issues, such as work-life balance topics to process reengineering, to management that will be taken seriously, and perhaps acted on."

Considering the stages, and the participants' responses, the analysis identified three separate dimensions of engaging in voice at work. The first dimension of engaging in voice, the power of the idea, refers to the experience of participants expressing their voice upward to their supervisors. The second dimension of engaging in voice, the "rifle approach" to communication, details the process of formulating and articulating ideas where the ideas can be heard and acted upon. The third dimension, impact of the supervisor, captures the variables of the dyadic relationship between the individual respondent and his/her supervisor.

The power of the idea represents the experience of speaking upward to management in terms of what and why. What refers to the idea itself, and why refers to why participant's felt the idea had power. Participants talked with passion about the various ideas they communicated to their leadership with the overarching goal of improving some aspect of their workgroup or organization. These ideas ranged from information technology solutions, developing standard operating procedures (SOP), enterprise-wide employee engagement, and developing and implementing health and wellness initiatives. See Figure 1. 


\section{FIGURE 1}

\section{ENGAGING IN EMPLOYEE VOICE}

\begin{tabular}{|c|c|c|}
\hline \multicolumn{3}{|c|}{ Engaging in Employee Voice } \\
\hline $\begin{array}{l}\text { Power of an Idea } \\
\text { - Addressing Problem } \\
\text { - Feeling Valued } \\
\text { - Supporting Colleagues (E) } \\
\text { - Impacting the Mission (E) }\end{array}$ & $\begin{array}{l}\text { Rifle Approach to Communication (E) } \\
\text { - Refining Solution (E) } \\
\text { - Obtaining Buy-In (E) } \\
\text { - Timing of Communication (E) }\end{array}$ & $\begin{array}{l}\text { Impact of Supervisor } \\
\text { - Leadership Style and Process } \\
\text { - Fostering Openness and Trust } \\
\text { - Feeling Autonomous }\end{array}$ \\
\hline
\end{tabular}

Participants shared that knowing that their ideas would address a workgroup or agency problem resulted in engaging in voice. The source of this idea was based on experience or at the request of their supervisors. Lorenzo, for example, talked about how he seized on an opportunity to respond to his supervisor's request:

I recall being at a meeting, and the Deputy Director was heading the meeting, and there may have been about eight of my colleagues. We were all subordinates to this Deputy Director. And so, he was explaining, rather talking about how a couple of our processes needed a fix. They needed to be revamped in a way, and so I just happened to say, "I believe I know how I can fix this process." I went on to explain on how we can make this process better.

Some participants articulated ideas based on their own initiative. For example, Gabrielle talked about an idea she wanted to implement into her agency:

A policy came down internal to our agency that allowed for a certain number of hours within a pay period to do health and wellness. I think there are less than five branches or divisions within my office that are implementing it. My division is not implementing it. So, I had a random thought of implementing it and allowing employees to engage in their health and wellness, which would improve their performance and well-being. We've had several employees that have suffered from heart attacks and illnesses.

Decisions to share ideas upwards were impacted by their impact on participant's colleagues. For example, Gabrielle stated, "I think my biggest driver is determining what it is going to do to the employees. What benefits are the employees going to get from this that will also benefit the organization and our customers?" Further, Isaac stated, "I think it would be that ability to have impact. To have an engagement or job where a lot of people think it matters." And Joyce articulated, "I would not necessarily be silent if there is something that I think would be important to other people even if it goes nowhere I would sill voice my concern. I would find a way to do it differently...I would still let my concerns be made known."

"Rifle approach to communication" represented a participant's belief that how they communicated their ideas could result in a better chance at being heard and acted on. To improve this chance of success, participants talked about strategies implemented before presenting information upward to their supervisor(s). The tasks identified by participants included performing due diligence, sharing information and seeking feedback from stakeholders, requesting insight from their supervisors, and understanding 
right time for communicating ideas. One participant, Isaac, stated, "I had a boss at another job before I came into the government, and he would say to me "when you come in here (to my office), you have a rifle with a scope, right. You hit the target about what you want to talk to me about." Based on analysis of participant responses, three sub-dimensions emerged from the data: (a) refining the solution, (b) obtaining buy-in, and (c) timing of communication.

Participants shared examples of strategies and planning for maximizing their chances for successfully exercising their voice. Additionally, they talked about the need for having clarity regarding information about the problem being addressed and developing a clear solution before presenting it to their supervisors and leadership. For example, Isaac expressed:

For me personally, I want to know that I have a full understanding of whatever the issue is, and that I have thought it through to give my superior a clear idea of what I think should be done and what the problem is. Generally, I am the kind of person who likes to have enough information and to be very sure about what I am going to say to somebody if I think there is something that is a true problem or not.

Other participants talked about putting their ideas in the best position to succeed. Van stated, "I want to have my due diligence done, and I have the right amount of research done. The way I see it is that if I come to you with the correct information, whether you accept it or reject it, I have done my part." Participants also talked about importance of obtaining buy-in from their supervisor and stakeholders plays in decisions to share ideas upwards. Isaac, explained his process this way:

We had also reached out to several individuals and got their input and feelings and perspective about their workload, and how it has changed over time. So, we had good perspectives of staff, we had data that was reliable in terms of what it was showing, and it was a clear-cut message.

Participants often shared the importance the role of their supervisor's leadership style, or practices, in their decision to communicate upward. These practices included interacting with their employees and peers, crafting of job functions, and setting a tone for the workgroup influence the office culture and their employees' decision to engage in voice. Gabrielle identified her supervisor's style as part of the reason why she communicates ideas upwards, "His leadership style. He is open to ideas. He listens to his employees, and he allows us to try different things. So far, I have not heard a 'no' from him regarding ideas or possibilities. It is more so, 'try it." Oscar expressed the following about his supervisor, "My immediate supervisor is terrific. He involves me and is concerned about me. I see him daily. He even pops his head in my office to see how things are going." Alberto echoed the same impact of his supervisor:

Her leadership style was very hands-off, which gave me the freedom to work with new concepts and implement them. It made me want to increase my accountability because she had that faith in me. I wanted to be sure that I was letting her know that the faith she had in me was valid.

Another factor that fostered upwards communication was the creation of a culture of creativity and freedom to take risks. Openness and trust have been identified as factors in creating transparent and safe culture. Nadine provided an excellent response about her supervisor when she commented,

Our relationship, he was very supportive with my work, and continuing to grow and to develop me as an employee. It is important to have those open dialogues. So, feeling like you trust your supervisor with certain things is important. 
Chantal talked about openness as a primary factor in her decision to exercise voice.

The working relationship with my supervisors. Their interaction with the rest of the staff or others in different departments. Their openness in terms of willingness. Mostly, how they interact with me when we are engaged and discussing work. You can tell when people are open or not. Their body language, which is something I pay attention to. How does the manger feel about change in general? I pay attention to how my manager reacts to those types of feelings about the meeting and change.

\section{How Do Public Sector Employees Experience Silence?}

Participants in this study suggested that experiences of engaging in silence were based on several factors. Van, admitted, "I did not know about employee silence. I had to Google it to figure out what it was. But I didn't know that employee silence was a topic of discussion." Despite this lack of awareness, participants identified various aspects of employee silence and conceptualized silence based on the following factors: (a) the employee chooses to withhold information or not speak about an idea, (b) the employee's beliefs that his/her supervisor or leadership will not listen to, or act on his/her idea, and (c) the employee's beliefs, due to culture and/or their leadership, that speaking their idea may result in an adverse consequence.

Three separate dimensions of engaging in silence were identified within our participants' experience. The first dimension of engaging in employee silence-feeling insecure-referred to the reasons that respondents felt they lacked the confidence to articulate their conceptualized idea. The second dimension-effect of being shot down - captures the impact of previous voice attempts that were not listened to or acted on. The third dimension-impact of the supervisor-documents participants' responses about how their direct supervisor made them choose to not communicate ideas. See Figure 2.

FIGURE 2

ENGAGING IN SILENCE

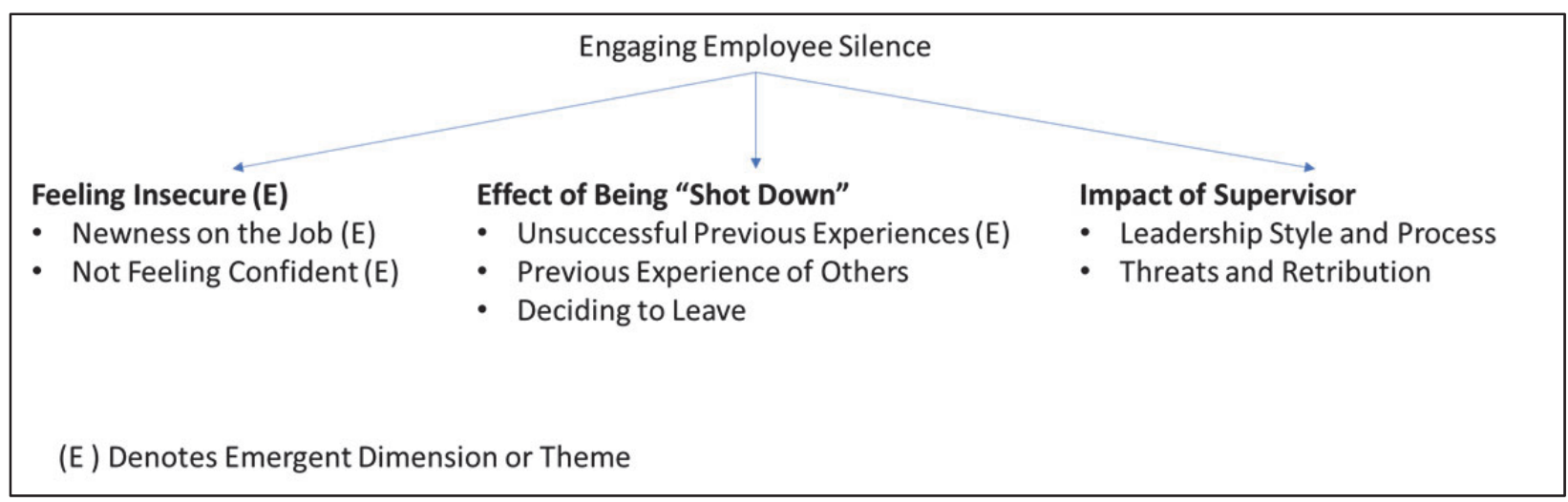

Participants shared that when they feel insecure about themselves or their job, they choose to not share ideas with supervisors and leaders. Participants talked about some of the reasons they felt drive this insecurity and, ultimately, their decision to remain silent about ideas. Some of these reasons included feeling of having personality flaws, being new to that specific job, and being new to a culture. Additionally, participants with managerial responsibility routinely discussed how their supervisor's newness to a job impacted not only their voice, but also their staff decision to communicate ideas. Van articulated it this way:

When I saw the definition and I applied it to me, there are certain things, for whatever reason good or bad, I don't bring up. Whether or not it is because I don't have the 
confidence, or I don't like taking certain risks, that is something I identified with, and I ask myself why people won't bring things forward.

Additionally, participants expressed that lack of confidence that their ideas will be received successfully resulted in participants identifying their personal flaws as a reason why their ideas were not shared. Additionally, participants expressed thoughts on the culture on the workgroup organization.

Van talked about his struggle with confidence when asked if he had ideas that he did not communicate upward:

Yes, there were a couple. And, they're more along the lines of when I had ideas or theories in my head or certain things...The main one was that I wasn't confident enough to bring it to their attention. Another one would be that in my mind that it was not the right time or place for that idea, and it would be something that I would have to work through to ensure that it is a viable idea to bring to them. If I bring it to my management, I want to ensure that it is something that I can do, and I can maintain, and that they can find benefit versus coming to them with various theories

When asked about the source of this lack of confidence, Van explained, "That's more a personality flaw for me. There are instances where I feel confident, but in instances where I don't understand the risks, or there are high-risks, my confidence goes down."

The next factor identified as a hindrance to communicating ideas was based on unsuccessful attempts to communicate ideas, and how their supervisor chose to act or respond drove their decisions to not communicate future ideas upward. Interestingly, several participants referred to feeling their ideas had been "shot down" or they were being "shut down." Based on the idea that was articulated, participants expressed that their supervisors' response, or lack thereof, made them no longer want to communicate upward. As Gabrielle stated:

I know of situations where people have gotten burned out regarding bringing up ideas on how we can do things better, and the ideas not going anywhere. They became fed up and they just shut down. They don't bring ideas forward anymore. I don't know if I would go that far, but I do believe it contributed to employees becoming complacent.

As another example, Oscar talked about his experience responding to a tasker from his leadership:

Um, I spent some time on it. Maybe an hour or two. I put together a list of about ten or so, project and evaluation ideas. About what we might do in the coming year. I never heard back from anybody; I stopped doing that. Occasionally, they might ask us for ideas, but I never did it again.

Further, to explain his rationale, Oscar added,

One, like I wasn't being listened to, and two, like I didn't need to do this again...I wouldn't say worthless, but (I felt) not valued as an employee. I had gone from being a high and ambitious performer to someone who just punches a clock.

Participants shared experiences of not sharing ideas with leadership because they had already decided to seek employment elsewhere Additionally, some participants decided to not communicate ideas and wait upon their first opportunity to retire from Federal service. These beliefs were based on witnessing or hearing about previous unsuccessful attempts by their peers and colleagues. One participant, Lorenzo, expressed why he stopped sharing ideas with his leadership, 
I really don't know because I am in an area now where I don't do (that work). I could make some improvements ...I think they would be appreciated, but my goal right now is to move on. I filed an EEO (Equal Employment Opportunity) complaint against the current leadership.

The next aspect articulated by participants was the belief that their day-to-day interaction with their supervisor drives the decision to engage in silence and not share ideas, issues, and concerns to improve the workgroup or organization. Participants expressed concerns such as being ignored, threatened, and encountering a difficult communication structure established by the supervisor. This frustration in the interaction with supervisors captured by Rebekah:

Sometimes, we have one-on-one meetings because we have had trouble in our relationship. Her leadership style impacts me by feeling discouraged and that I don't have a voice, which I have told her openly. I have told her that I feel discarded.

Two sub-dimensions emerged from the data, which were leadership style and process and threats and retribution.

Participants' belief that their supervisor's leadership methodology and processes make them not want to share ideas with said supervisor. And, participants articulated that supervisors created a communication structure that fostered the engagement of silence. These beliefs have been implicitly mentioned as part of other themes; and they were based on witnessing or hearing about previous unsuccessful attempts by their peers and colleagues. Lorenzo, shared his thoughts about his supervisor's leadership style:

I had worked for this person for a couple of years, and I think one begins to see and understand another person's personalities, and their characteristics and traits. I knew that at that time that there was no way I was going to be able talk in private, even if I wanted to. I tried my best to avoid this person as much as possible.

Lorenzo continued, and talked about his current supervisor, "I have ideas now that I don't take forward because I work for another toxic leader. I think that I would get the same result with the other leader. So, I just don't take any ideas forward." Nadine expounded on the importance of reliance on the supervisor has when decided to not upward communicate:

If there is not trust or respect. It depends and is very situation specific for me...I think those are the two predominant factors for me. Right now, my supervisor is kind of done with his role, and expects you to be very responsive immediately when he requests things of you, but the opposite is not true. So, if you need something from him, and we are constantly doing different things and we are not directly under him, so it makes things difficult.

\section{What Is the Relationship between Employee Engagement and Employee Voice \& Employee Silence?}

The results of this study indicated that participants' decisions to upward communicate ideas to engage in voice, or to engage in silence, to their supervisors and skip-level leaders is driven by their engagement state. This finding expands on the employee engagement research and broadens its application into the conversation about both voice and silence. Detert and Burris (2007) suggested that employee voice and silence should be positioned as a discretionary act by employees. Further, Shuck and his colleagues (2011) found that discretionary acts by employees are outcomes of employee engagement, not antecedents, positioning the act of both voice and silence as outcomes of employee engagement. Consequently, the results of this study would appear to align an employee's decision to engage in voice or silence as a result of their engagement state and thus, as an outcome of engagement. These findings 
contradict employee voice (and silence) encountered in previous employee engagement research. For example, Macleod and Clarke (2009) suggested that employee voice and silence were drivers of an employee's engagement state and further, Rees and her colleagues (2013) found that employee voice was a factor that determined employee engagement. Our research suggests a different positioning of engagement.

Specifically, participants provided narrative-based justifications for the sequential order of employee engagement and then acting on voice or silence. In terms of voice, justifications included feelings of empowerment, creativity, the impact of relationship with their supervisors, and job affect. Justifications of silence included feelings of exhaustion, complacency, poor supervisor relationship, and depression. Both sets of justifications parallel and validate Kahn's (1990) antecedents of engagement: (a) psychological meaningfulness, (b) psychological safety, and (c) psychological availability. Additionally, viewing the other conclusions from the prism of employee engagement instead of employee voice and silence aligns with Kahn's antecedents.

\section{Discussion}

This study's findings validate and expand previous research that the supervisor's style, process, and relationship with the employee has a profound impact on employee decisions to communicate ideas, thoughts, and concerns (ideas) upward to leadership. This conclusion is represented by in-depth data analysis of participants' responses to the first two research questions and is in line with both the prevailing voice (Detert \& Burris, 2007) and silence (Morrison, 2014) research. Detert and Burris (2007) found that leadership behaviors have the strongest impact employee voice. Conversely, Morrison (2014) suggested that behavior of supervisors and leaders could create barriers to employee voice - and our work supports both positions. Additionally, these findings are in alignment with Kahn's (1990) qualitative research regarding the impact supervisor relationships have with an employee's overall state of engagement. As a part of the psychological safety subdimension, Kahn (1990) suggested that supportive and resilient leadership created and environment that resulted in employee openness and creativity.

Specific to engaging in voice, this study makes the case that supervisors who exhibit a leadership style that fosters trust had the greatest propensity for cultivating a culture that resulted in employee voice. The creation of this voice-culture fostered a sharing of ideas and an openness to creativity. This finding was aligned with research by Rees and her colleagues (2013), who indicated that trust mediated the relationship between employee voice and his/her supervisor. Additionally, a supervisor's leadership style that helps employees feel empowered and independent drove an employee's decision to engage in their discretionary voice overtime. This conclusion was aligned to research by Gao and his colleagues (2011), which identified a direct relationship between a leaders' empowering styles and an employee's decision to engage in voice.

Conversely, this study suggested that a supervisor's leadership style could create a relationship with the participant that also resulted in the decision to choose silence. A leadership style that did not make the participant feel they were operating in a culture that was trusting resulted in employees not taking risks and not being creative, which was an artifact of silence. This work affirms earlier research by Detert and Trevino (2010) who found that supervisors' (and skip-level leaders') style could have a positive or negative impact on an employee's decision to engage in voice or silence.

Additionally, leadership behavior that resulted in participants feeling threatened or intimidated led to participants engaging in silence. Leaders who responded to upward communication in a way that could be interpreted as intimidating, challenging and bothered impacted participant's decisions to engage in silence going forward. This finding is aligned with Pinder and Harlos (2001), who argued supervisors that create an environment of fear and intimidation fosters employees engaging in silence regarding improving their organization. 


\section{IMPLICATIONS AND CONCLUSIONS}

This study has several implications for both academic research and practical application. First, our study makes the argument that employee engagement scholars broaden their employee voice (and silence) research to determine whether it is a driver or outcome of employee engagement. Participants in this study felt their decisions to exercise voice and/or silence were outcomes of their engagement state. These beliefs align with employee voice scholars positioning of the concept as a discretionary act. Second, employee engagement research should start to include employee silence as a construct. In this study, participants' relationship with their supervisor impacted decisions to exercise both voice and silence. However, additional silence findings were identified.

Further research may identify other drivers of employee silence and develop ideas to minimize its impact. Regarding U.S. federal government research, this study makes the case that further qualitative research may be fruitful to uncover new causes of both engagement and disengagement. While Kahn (1990) laid a research foundation as a qualitative research, most U.S. federal government research focuses on quantitative correlations of the Federal Employee Viewpoint Survey (FEVS) data. Leadership development practices could also expand to address competencies that could foster an employee voice culture and minimize silence. This study makes the case that drivers of employee engagement, such as trust, risk, value, confidence, insecurity, fear, and empowerment impact both employee voice and employee silence. Strengthening these leadership competencies can help to foster a strong voice culture where all ideas.

This is the first qualitative study to simultaneously explore the relationships between employee engagement, employee voice, and employee silence as they relate to public sector employees in the United States. Hopefully, this the work will encourage new research and practices, and begin a muchneeded dialogue between and within established scholars of engagement, voice, and silence.

\section{REFERENCES}

Albrecht, S. L., Bakker, A. B., Gruman, J. A., Macey, W. H., \& Saks, A. M. (2015). Employee engagement, human resource management practices and competitive advantage. Journal of Organizational Effectiveness: People and Performance, 2(1), 7-35. doi:https://doi.org/10.1108/JOEPP-08-2014-0042

Alfes, K., Truss, C., Soane, E. C., Rees, C., \& Genenby, M. (2010). Creating an engaged workforce: Findings from the kingston employee engagement consortium project. Chartered Institute of Personnel and Development, (January), 1-61. Retrieved from https://www.academia.edu/1859028/Creating_an_Engaged_Workforce_CIPD_Research_Report 2010

Alfes, K., \& Leloglu, S. (2013). Case studies in employee engagement. In C. Truss, R. Delbridge, K. Alfes, \& E. Soane (Eds.), Employee engagement in theory and practice. London: Routledge (Kindle Edition).

Barry, M., \& Wilkinson, A. (2015). Pro-social or pro-management? A critique of the conception of employee voice as a pro-social behaviour within organizational behaviour. British Journal of Industrial Relations. doi:https://doi.org/10.1111/bjir.12114

Crawford, E., Rich, B., Buckman, B., \& Bergeron, J. (2013). The antecedents and drivers of employee engagement. In C. Truss, R. Delbridge, K. Alfes, A. Shantz, \& E. Soane (Eds.), Employee engagement in theory and practice. Cheltenham: Routledge (Kindle Edition).

Creswell, J. (2013). Qualitative inquiry and research design: Choosing among five approaches. Thousand Oaks, CA: SAGE Publications (Kindle Edition).

Detert, J., \& Burris, E. (2007). Leadership behavior and employee voice: Is the door really open? Academy of Management Journal, 50(4), 869-884. doi:https://doi.org/10.5465/amj.2007.26279183 
Detert, J., \& Trevino, L. (2010). Speaking up to higher-ups: How supervisors and skip-level leaders influence employee voice. Organization Science, 21(1), 249-270. doi:https://doi.org/10.1287/orsc. 1080.0405

Forman, J., \& Damschroder, L. (2008). Qualitative content analysis. Theoretical foundation. Empirical Methods for Bioethics: A Primer, 11, 39-62. doi:https://doi.org/10.1016/S1479-3709(07)11003-7

Gao, L., Janssen, O., \& Shi, K. (2011). Leader trust and employee voice: The moderating role of empowering leader behaviors. The Leadership Quarterly, 22(4), 787-798. doi:https://doi.org/10.1016/j.leaqua.2011.05.015

Gruman, J., \& Saks, A. (2014). Being psychologically present when speaking up: Employee voice engagement. In A. Wilkinson, T. Dundon, J. Donaghey, \& R. Freeman (Eds.), Handbook of Research on Employee Voice (pp. 398-410). Cheltenham: Edward Alger.

Hirschman, A. (1970). Exit, voice and loyalty: Responses to decline in firms, organizations and states. Cambridge, MA: Harvard University Press.

Kahn, W. (1990). Psychological conditions of personal engagement and disengagement at work. Academy of Management Journal, 33(4). doi:https://doi.org/10.2307/256287

Kassing, J. (2002). Speaking up: Identifying employees' upward dissent strategies. Management Communication Quarterly, 16(2), 187-209. doi:https://doi.org/10.1177/089331802237234

Lavigna, R. (2013). Engaging goverment employees: Motivate and inspire your people to achieve superior performance. Washington, D.C.: AMACOM.

Lloyd, R. (2008). Discretionary Effort and the performance domain. The Australian and New Zealand Journal of Organisational Psychology, 1, 22-34. doi:https://doi.org/10.1375/ajop.1.1.22

Macleod, D., \& Clarke, N. (2009). Engaging for success: Enhancing performance through employee engagement. Department for Business Innovation \& Skills, 1. doi:https://doi.org/Book Review

May, D. R., Gilson, R. L., \& Harter, L. M. (2004). The psychological conditions of meaningfulness, safety and availability and the engagement of the human spirit at work. Journal of Occupational and Organizational Psychology, 77(1), 11-37. doi:https://doi.org/10.1348/096317904322915892

Milliken, F., Morrison, E., \& Hewlin, P. (2003). An Exploratory Study of Employee Silence: Issues that Employees Don't Communicate Upward and Why. Journal of Management Studies, 40(6), 14531476. doi:https://doi.org/10.1111/1467-6486.00387

Morrison, E. (2011). Employee voice behavior: Integration and directions for future research. The Academy of Management Annals, 5(1), 373-412. doi:https://doi.org/10.1080/19416520.2011.574506

Morrison, E. (2014). Employee voice and silence. Annual Review of Organizational Psychology and Organizational Behavior, 1(1), 173-197. doi:https://doi.org/10.1146/annurev-orgpsych-031413091328

Morrison, E., \& Milliken, F. (2000). Organizational silence: A barrier to change and development in a pluralistic world. Academy of Management, 25(4), 706-725. doi:https://doi.org/10.5465/AMR.2000.3707697

Mowbray, P. K., Wilkinson, A., \& Tse, H. H. M. (2014). An integrative review of employee voice: Identifying a common conceptualization and research agenda. International Journal of Management Reviews, 17, 1-19. doi:https://doi.org/10.1111/ijmr.12045

Pinder, C., \& Harlos, K. (2001). Employee silence: Quiescence and acquiescence as responses to perceived injustice. Research in Personnel and Human Resource Management, 20, 331-369. doi:https://doi.org/10.1016/S0742-7301

Robinson, R. (2017). Staying on track in times of change. Public Manager. Retrieved from https://www.td.org/magazines/the-public-manager/staying-on-track-in-times-of-change

Saldana, J. (2016). The coding manual for qualitative researchers (3rd ed.). Thousand Oaks, CA: Sage Publications.

134 Journal of Organizational Psychology Vol. 19(4) 2019 
Shuck, B., Ghosh, R., Zigarmi, D., \& Nimon, K. (2012). The jingle jangle of employee engagement: Further exploration of the emerging construct and implications for workplace learning and performance. Human Resource Development Review, 12(1), 11-35. doi:https://doi.org/10.1177/1534484312463921

Shuck, B., \& Rose, K. (2013). Reframing employee engagement within the context of meaning and purpose: Implications for HRD. Advances in Developing Human Resources, 15(4), 341-355. doi:https://doi.org/10.1177/1523422313503235

Shuck, B., Reio, T., \& Rocco, T. (2011). Employee engagement: An examination of antecedent and outcome variables. Human Resource Development International, 14(4), 427-445. doi:https://doi.org/10.1080/13678868.2011.601587

Tangirala, S., \& Ramunujam, R. (2008). Employee silence on critical work issues: The cross level effects of procedural justice climate. Personnel Psychology, 61, 37068. doi:https://doi.org/10.1111/j.1744-6570.2008.00105.x

Vakola, M., \& Bouradas, D. (2005). Antecedents and consequences of organisational silence: An empirical investigation. Employee Relations, 27(5), 441-458. doi:https://doi.org/10.1108/01425450510611997

Van Dyne, L., Kamdar, D., \& Joireman, J. (2008). In-role perceptions buffer the negative impact of low LMX on helping and enhance the positive impact of high LMX on voice. The Journal of Applied Psychology, 93(6), 1195-1207. doi:https://doi.org/10.1037/0021-9010.93.6.1195

Wollard, K., \& Shuck, B. (2011). Antecedents to Employee engagement: A structured review of the literature. Advances in Developing Human Resources, 13(4), 429-446. doi:https://doi.org/10.1177/1523422311431220

Zhang, Y., \& Wlidemuth, B. (2009). Qualitative analysis of content. In B. Wildemuth (Ed.), Applications of social research methods to questions in information and library science (pp. 308-319). Westport, CT: Libraries Unlimited. 